\title{
Acculturation and oral health status among tibetan immigrants residing in Bangalore City, India
}

\author{
G. Radha ${ }^{1}$, K. Pushpanjali ${ }^{2}$, Aruna C.N. ${ }^{3}$ \\ ${ }^{1}$ M.D.S. Reader, Dept of Public Health Dentistry, V.S. Dental College and Hospital, Bangalore. \\ ${ }^{2}$ M.D.S. Prof \& Head . Dept of Public Health Dentistry. M.S.Ramaiah Dental College and Hospital, Bangalore. \\ ${ }^{3}$ M.D.S. Assistant Professor. Dept of Public Health Dentistry. Raja Rajeshwari Dental College and Hospital. Bangalore.
}

Correspondence:

Dept of Public Health Dentistry

V.S. Dental College and Hospital

Bangalore

E-mail:s_sujathajanardhan@yahoo.com

Received: $18 / 12 / 2010$ Accepted: $27 / 03 / 2011$
Radha G, Pushpanjali K, C.N. A. Acculturation and oral health status among tibetan immigrants residing in Bangalore City, India . J Clin Exp Dent. 2011;3(4):e274-9. http://www.medicinaoral.com/odo/volumenes/v3i4/jcedv3i4p274.pdf
Article Number: $50457 \quad$ http://www.medicinaoral.com/odo/indice.htm (C) Medicina Oral S. L. C.I.F. B 96689336 - eISSN: 1989-5488

eMail: jced@jced.es

\begin{abstract}
Background: This study is the first of its kind conducted among Tibetans immigrants to Bangalore City, India to study the effects of acculturation on the oral health outcomes of less established group of individuals.

Objectives: To determine the Acculturation and oral health status among Tibetan immigrants in Bangalore city and to assess the relationship between them.

Materials and Methods: A random sample of 560 immigrants aged 18 years and above from different Tibetan centre of Bangalore city were included for the study. Acculturation was measured using modified Psychological-behavioral acculturation scale. Dental caries experience and periodontal status were recorded. Results: $49.1 \%$ of females and $50.9 \%$ of males were in highly accultured group. Bivariate analysis using Chi-square test was performed using $5 \%$ significance level. Logistic regression analysis demonstrated a strong association between DMFT and Ethnic factors, and periodontal status with language barrier and utilization of health care.

Discussion: Reducing disparities in oral health status and in the use of dental services among Tibetan immigrants require attention to cultural factors such as language barrier and age at migration and immigrant's degree of acculturation.
\end{abstract}

Key Words: Acculturation, oral health status, oral health beliefs, Tibetan Immigrants, Bangalore City. 


\section{Introduction}

Acculturation is a complex phenomenon that can serve as a proxy for cultural norms and behaviors affecting care seeking, prevention behaviors, and ultimately, health outcomes $(1,2$, and 3$)$. This process does not occur at the same rate or to the same degree in all individuals. Various studies of the effect of acculturation on the general health of immigrants have shown that acculturation can be beneficial to some health behaviors and outcomes due to preventive health care services and detrimental to others by adopting negative behavioral practices $(4,5)$.

Bangalore, being the third largest metropolitan city in India is one of the most happening cities in the world. There are large number of immigrants from the neighboring countries in search of job opportunities and better living conditions. Since their exodus in 1959, a few Tibetans have made Bangalore their home. Culture of Bangalore is an amalgam of many cultures. Assimilation of one cultural group into another group is evidenced by adoption of common attitudes and values.

Acculturation has been studied in relation to prevalence of chronic illness and utilization of health services. As people move from one culture and adopt another culture, the degree of acculturation can affect the immigrants' decisions to change the life style and behavioral change, including those related to health (6). Limited research data are available to describe the differences in oral health care pattern among the various immigrants in India and especially among the Tibetans. The move away from Tibet has brought about dramatic changes in the Tibetan culture and health of the people. Hence an attempt is made to assess the relationship between acculturation and oral health status among the Tibetan immigrants of Bangalore city.

\section{Methodology}

The study is based on cross sectional survey data collected from a sample of 560 individuals aged 18 years and above in different Tibetan centre's of Bangalore city. Simple random sampling was used for sample selection. Individuals in the age group of 15-45 years of age were included in the study and an informed consent was obtained from study subjects prior to participation in the study.

Acculturation was measured using modified psychological behavioral acculturation scale ${ }^{4}$, which comprised of language, knowledge and media use, social interactions, food preferences and self-identification items.

A self-administered questionnaire consisting of 24 items was pre validated by pilot study. Each question was categorized into low and high acculturation scale. The acculturation score ranging between $0-12$ was considered as low and score between 12-24 as high acculturation. Basic data on socio demographic characteristics of subject's age, gender, education, occupation, income levels, marital status, age at migration, duration of stay in Bangalore, access to dental care and previous dental visits was collected.

Following the completion of questionnaire an oral health assessment was carried out for caries experience (DMFT and DMFS index of Knutson and Palmer 1938), Periodontal status (CPI index 1997) and Fluorosis (Deans Fluorosis index 1945) by two calibrated examiners and trained recorders. The examination was done by using diagnostic instruments such as mouth mirror, explorer and CPI probe under artificial light.

Data analysis

Data was entered into excel sheets and exported to SPSS version 14.0 for statistical analysis. Descriptive statistical analysis and Bivariate analysis were performed. The dependent variables DMFT and Periodontal status were dichotomized as presence or absence of the condition. Bivariate analysis using Chi-square test was performed at 5\% significance level. Then Logistic regression analysis using stepwise procedure was performed to identify the acculturation factors which were at more risk to develop dental caries and periodontal disease.

\section{Results}

Table 1 shows the frequencies for socio demographic characteristics such as age, gender, education, occupation, Socio-economic status and marital status. The study consisted of 560 individuals, of whom $52 \%$ were male and $48 \%$ were females. Most of the individuals (59.3\%) were in age group of $15-24$ years. $72.5 \%$ were in upper lower socio-economic status, $98.5 \%$ have used tooth brush and tooth paste and $64.8 \%$ brushed once daily. Only $7 \%$ had the habit of smoking, $51.1 \%$ were affected by dental caries, mean DMFT 3.6\%. 82.5\% had gingivitis and $7.5 \%$ had periodontal involvement. $17.8 \%$ had dental fluorosis and is seen more among first generation group, the reason may be the endemic fluorosis.

Table 2 shows Acculturation data of the study population. $49.1 \%$ of females and $50.9 \%$ of males were in highly accultured group. Among 15 to 24 year olds who form the majority of the study population, $57.1 \%$ were highly accultured and $62.9 \%$ were in low acculturation. Among those affected by Dental caries, 57\% were highly accultured. Among those with periodontal involvement, $17.1 \%$ were highly accultured.

Table $3 a$ and Table 3b: Data was subjected to Bivariate analysis. Those with $p$ value less than 0.05 were subjected to logistic regression analysis.

Table 4a: Stepwise logistic regression analysis with DMFT as dependent variable. Statistically significant factor in this model was music preferred $(\mathrm{p}<0.05)$.

Table 4b: Stepwise logistic regression analysis with Periodontal status as dependent variable. Among the variables subjected for logistic regression analysis with pe- 


\begin{tabular}{|c|c|c|}
\hline Variables & Number & Percentage \\
\hline $\begin{array}{l}\text { Age Group } \\
15-24 \mathrm{yrs} \\
25-34 \mathrm{yrs} \\
35-44 \mathrm{yrs} \\
45 \mathrm{yrs} \text { and above }\end{array}$ & $\begin{array}{l}332 \\
122 \\
98 \\
8\end{array}$ & $\begin{array}{l}59.10 \% \\
21.70 \% \\
17.40 \% \\
1.50 \%\end{array}$ \\
\hline $\begin{array}{l}\text { Gender } \\
\text { Male } \\
\text { Female }\end{array}$ & $\begin{array}{l}292 \\
268\end{array}$ & $\begin{array}{l}52 \% \\
48 \%\end{array}$ \\
\hline $\begin{array}{l}\text { Education } \\
\text { Primary school } \\
\text { High school } \\
\text { Graduate }\end{array}$ & $\begin{array}{l}38 \\
68 \\
454\end{array}$ & $\begin{array}{l}6.80 \% \\
12.10 \% \\
81 \%\end{array}$ \\
\hline $\begin{array}{l}\text { Occupation } \\
\text { Unskilled worker } \\
\text { Semiskilled } \\
\text { Skilled } \\
\text { Clerical/Shop } \\
\text { Semiprofessional }\end{array}$ & $\begin{array}{l}6 \\
86 \\
102 \\
360 \\
6\end{array}$ & $\begin{array}{l}1.1 \% \\
15.3 \% \\
18.2 \% \\
64.2 \% \\
1.1 \%\end{array}$ \\
\hline $\begin{array}{l}\text { Socioeconomic status } \\
\text { Lower } \\
\text { Upper lower } \\
\text { Lower middle } \\
\text { Upper middle } \\
\text { Upper }\end{array}$ & $\begin{array}{l}0 \\
406 \\
112 \\
42 \\
0\end{array}$ & $\begin{array}{l}0 \\
72.5 \% \\
20 \% \\
7.5 \% \\
0\end{array}$ \\
\hline $\begin{array}{l}\text { Marital status } \\
\text { Married } \\
\text { Unmarried }\end{array}$ & $\begin{array}{l}338 \\
222\end{array}$ & $\begin{array}{l}60.4 \% \\
39.6 \%\end{array}$ \\
\hline
\end{tabular}

Table 1. Sociodemogarphic data riodontal disease, Language preferred and place of birth were found to be statistically significant $(\mathrm{p}<0.05)$.

\section{Discussion}

There is scarcity of data available on oral health among Tibetan immigrants in India. The move from Tibet has brought about dramatic changes in their culture and health. Evidence from Tibetan health workers has suggested an extremely poor dental health situation among the Tibetans and their children in their new environment (7).

In this study, acculturation was measured using modified psychological behavioral acculturation scale. Psychological acculturation reflects the degree of consensus with defined norms, basic values, beliefs, attitudes and preferences of the majority of the group. Behavioral acculturation is related to the cultural learning and the adoption of the most observable, external aspects of the dominant culture including social skills, language skills and lifestyle and the ability to fit into the new socio cultural reality. It was found that $49.1 \%$ of females and $50.95 \%$ of male were in high acculturation group and $49.05 \%$ of males and $50.89 \%$ of females were in low acculturation group. These results are similar to the studies conducted by Jiro Otsuru (8) where $92 \%$ of migrants to Japan were in low acculturation group.

Dental caries experience was almost similar in both high and low acculturation group, $57 \%$ and $58 \%$ respectively. In a study by Gustavo D. Cruz, Length of stay was inversely associated with need for treatment of dental caries (9). This process is related to acculturation where individuals modify values and behaviors as a result of

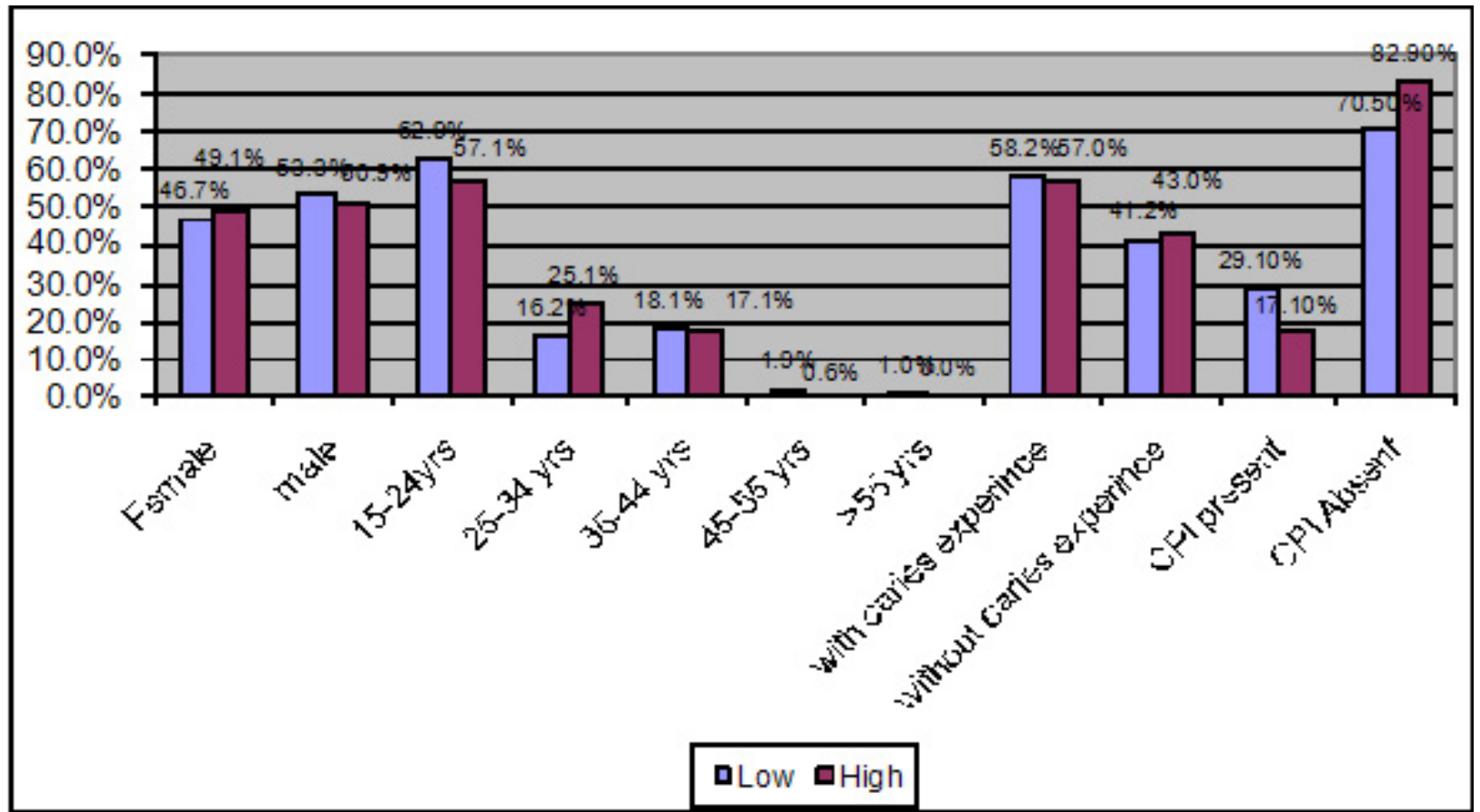

Table 2. Acculturation Data. 


\begin{tabular}{|c|c|c|c|}
\hline Acculturation Scale & DMFT $=0$ & DMFT $>0$ & P value \\
\hline \multicolumn{4}{|l|}{ 1.Language spoken } \\
\hline High acculturation & $70(12.5 \%)$ & $160(28.5 \%)$ & \multirow[t]{2}{*}{$<0.001 *$} \\
\hline Low acculturation & $152(27.1 \%)$ & $178(31.7 \%)$ & \\
\hline \multicolumn{4}{|l|}{ 2.Language preferred } \\
\hline High acculturation & $74(13.2 \%)$ & $158(28.2 \%)$ & \multirow[t]{2}{*}{$<0.001 *$} \\
\hline Low acculturation & $156(27.8 \%)$ & $172(30.7 \%)$ & \\
\hline \multicolumn{4}{|l|}{ 3.Place of birth } \\
\hline High acculturation & $150(26.7 \%)$ & $242(43.2 \%)$ & \multirow[t]{2}{*}{0.201} \\
\hline Low acculturation & $74(13.2 \%)$ & $94(16.7 \%)$ & \\
\hline \multicolumn{4}{|l|}{ 4.Place of growing up } \\
\hline High acculturation & $112(20.0 \%)$ & $146(26.0 \%)$ & \multirow[t]{2}{*}{0.128} \\
\hline Low acculturation & $112(20.0 \%)$ & $190(33.9 \%)$ & \\
\hline \multicolumn{4}{|l|}{ 5.Generation level } \\
\hline High acculturation & $70(12.5 \%)$ & $102(18.2 \%)$ & \multirow[t]{2}{*}{0.822} \\
\hline Low acculturation & $154(27.5 \%)$ & $234(41.7 \%)$ & \\
\hline \multicolumn{4}{|l|}{ 6.Food preferred } \\
\hline High acculturation & $102(18.2 \%)$ & $138(24.6 \%)$ & \multirow[t]{2}{*}{0.296} \\
\hline Low acculturation & $122(21.7 \%)$ & $198(35.3 \%)$ & \\
\hline \multicolumn{4}{|l|}{ 7.Music/Television } \\
\hline High acculturation & $218(38.9 \%)$ & $294(52.5 \%)$ & \multirow[t]{2}{*}{$<0.001 *$} \\
\hline Low acculturation & $6(1.1 \%)$ & $42(7.5 \%)$ & \\
\hline \multicolumn{4}{|l|}{ 8.Customs and Festivals } \\
\hline High acculturation & $160(28.5 \%)$ & $242(43.2 \%)$ & \multirow[t]{2}{*}{0.878} \\
\hline Low acculturation & $64(11.4 \%)$ & $94(16.7 \%)$ & \\
\hline \multicolumn{4}{|l|}{$\begin{array}{l}\text { 9.Difficulty in getting } \\
\text { Jobs }\end{array}$} \\
\hline High acculturation & $44(7.85 \%)$ & $178(31.7 \%)$ & \multirow[t]{2}{*}{$<0.001 *$} \\
\hline Low acculturation & $180(32.1 \%)$ & $158(28.2 \%)$ & \\
\hline \multicolumn{4}{|l|}{$\begin{array}{l}\text { 10. Utilization of health } \\
\text { services }\end{array}$} \\
\hline High acculturation & $86(15.3 \%)$ & $130(23.2 \%)$ & \multirow[t]{2}{*}{0.943} \\
\hline Low acculturation & $138(24.6 \%)$ & $206(36.7 \%)$ & \\
\hline \multicolumn{4}{|l|}{ 11.Age at migration } \\
\hline High acculturation & $170(30.3 \%)$ & $234(41.7 \%)$ & \multirow[t]{2}{*}{0.106} \\
\hline Low acculturation & $54(9.6 \%)$ & $102(18.2 \%)$ & \\
\hline
\end{tabular}

* denotes significant association

Table 3a. Bivariate analysis between acculturation Variable and $D M F T$

continuous exposure to a new cultural system, better access to dental care. Mean DMFT was found to be 3.6 as compared to 6.05 by Gustavo et al (10) Periodontal involvement was seen more in low acculturation group. Only $17 \%$ of high acculturation subjects had periodontal involvement. It could be due to majority of individuals brushed their teeth twice. Individuals with low acculturation and males had higher levels of periodontal disea-

\begin{tabular}{|c|c|c|c|}
\hline Acculturation Scale & Perio $<0$ & Perio $>0$ & Pvalue \\
\hline \multicolumn{4}{|l|}{ 1.Language spoken } \\
\hline High acculturation & $50(8.9 \%)$ & $176(31.4 \%)$ & \multirow{2}{*}{0.741} \\
\hline Low acculturation & $70(12.5 \%)$ & $264(47.1 \%)$ & \\
\hline \multicolumn{4}{|l|}{ 2.Language preferred } \\
\hline High acculturation & $70(12.5 \%)$ & $168(30 \%)$ & \multirow{2}{*}{$0.001 *$} \\
\hline Low acculturation & $58(10.3 \%)$ & $264(47.1 \%)$ & \\
\hline \multicolumn{4}{|l|}{ 3.Place of birth } \\
\hline High acculturation & $72(12.8 \%)$ & $320(57.1 \%)$ & \multirow{2}{*}{$0.002 *$} \\
\hline Low acculturation & $50(8.9 \%)$ & $118(21.0 \%)$ & \\
\hline \multicolumn{4}{|l|}{ 4.Place of growing up } \\
\hline High acculturation & $64(11.4 \%)$ & $194(34.6 \%)$ & \multirow{2}{*}{0.109} \\
\hline Low acculturation & $58(10.3 \%)$ & $244(43.5 \%)$ & \\
\hline \multicolumn{4}{|l|}{ 5.Generation level } \\
\hline High acculturation & $28(5 \%)$ & $144(25.7 \%)$ & \multirow{2}{*}{$0.035^{*}$} \\
\hline Low acculturation & $94(16.7 \%)$ & $294(52.5 \%)$ & \\
\hline \multicolumn{4}{|l|}{ 6.Food preferred } \\
\hline High acculturation & $52(9.2 \%)$ & $188(33.5 \%)$ & \multirow{2}{*}{0.952} \\
\hline Low acculturation & $70(12.5 \%)$ & $250(44.6 \%)$ & \\
\hline \multicolumn{4}{|l|}{ 7.Music/Television } \\
\hline High acculturation & $120(21.4 \%)$ & $392(70 \%)$ & \multirow{2}{*}{$0.001 *$} \\
\hline Low acculturation & $2(0.3 \%)$ & $46(8.2 \%)$ & \\
\hline \multicolumn{4}{|l|}{ 8.Customs and Festivals } \\
\hline High acculturation & $96(17.1 \%)$ & $272(48.5 \%)$ & \multirow{2}{*}{0.195} \\
\hline Low acculturation & $60(10.7 \%)$ & $132(23.5 \%)$ & \\
\hline \multicolumn{4}{|l|}{$\begin{array}{l}\text { 9.Difficulty in getting } \\
\text { Jobs }\end{array}$} \\
\hline High acculturation & $36(6.4 \%)$ & $86(15.3 \%)$ & \multirow{2}{*}{$0.019 *$} \\
\hline Low acculturation & $86(15.3 \%)$ & $352(62.8 \%)$ & \\
\hline \multicolumn{4}{|l|}{$\begin{array}{l}\text { 10.Utilization of health } \\
\text { services }\end{array}$} \\
\hline High acculturation & $58(10.3 \%)$ & $158(28.2 \%)$ & \multirow{2}{*}{$0.021 *$} \\
\hline Low acculturation & $64(11.4 \%)$ & $280(50 \%)$ & \\
\hline \multicolumn{4}{|l|}{ 11.Age at migration } \\
\hline High acculturation & $88(15.7 \%)$ & $316(56.4 \%)$ & \multirow{2}{*}{0.997} \\
\hline Low acculturation & $34(6.0 \%)$ & $122(21.7 \%)$ & \\
\hline
\end{tabular}

* denotes significant association

Table 3b. Bivariate analysis between acculturation Variable and Periodontal Status

se levels than those with high acculturation and females similar to study by Ismail \& Szpunar,(11). However the studies conducted by Marino R (12), Stewart et al, (13) and Cruz (14) showed that individuals with low acculturation status had a higher prevalence of decayed and missing and higher periodontal disease levels than those with high acculturation.

With respect to the oral hygiene practices followed 


\begin{tabular}{|l|l|l|l|l|}
\hline Variables & Significance & Odds Ratio & \multicolumn{2}{|c|}{$\begin{array}{c}\text { 95\% C.I. } \\
\text { Upper }\end{array}$} \\
\hline Language spoken & 0.054 & 0.558 & 0.310 & 1.010 \\
\hline Language preferred & 0.163 & 1.490 & 0.851 & 2.610 \\
\hline Music preferred & 0.008 & 0.182 & 0.052 & 0.643 \\
\hline Difficulty in getting jobs & 0.996 & 0.999 & 0.579 & 1.723 \\
\hline
\end{tabular}

Table 4a. Stepwise logistic regression analysis with DMFT as Dependent variable

\begin{tabular}{|l|l|l|l|l|}
\hline Variables & Significance & Odds Ratio & \multicolumn{2}{|c|}{$\begin{array}{c}\text { 95\% C.I. } \\
\text { Upper }\end{array}$} \\
\hline Language preffered & & 0.469 & 0.252 & 0.870 \\
\hline Music preffered & 0.016 & 0.137 & 0.018 & 1.050 \\
\hline Place of birth & 0.056 & 2.220 & 1.161 & 4.243 \\
\hline Utilization of Health care & 0.016 & 0.554 & 0.301 & 1.020 \\
\hline Generation level & 0.058 & 1.916 & 0.956 & 3.839 \\
\hline Difficulty in getting job & 0.067 & 0.603 & 0.306 & 1.190 \\
\hline
\end{tabular}

Table 4b. Stepwise logistic regression analysis with Periodontal status as Dependent variable

The Association of Immigration and Acculturation Attributes With Oral Health Among Immigrants in New York City

Gustavo D. Cruz, DMD, MPH, Yu Chen, PhD, Christian R. Salazar, MPH and Racquel Z. Le Geros, PhD

October 2009, Vol 99, No. S2 | American Journal of Public Health S474-S480

(C) 2009 American Public Health Association

$35 \%$ of Tibetan immigrants brushed their teeth twice daily. $18.46 \%$ of African immigrants to Philadelphia brushed twice a day in contrast with the $61.3 \%$ immigrants to New England, $90 \%$ of Latin American migrants to Japan brushed more than twice a day (8) and $80 \%$ of Hmong immigrants to U.S brushed twice day (15).

Consistent with the hypothesis that acculturation influences the use of health services, we found that the $60 \%$ of Tibetan immigrants seek oral health care from dentist compared to $49 \%$ visiting dentist among Hmong refugee population in US Christopher (15) and Okunseri et al (16) studies. This could be due to the reason majority of immigrants in our study were in high acculturation group.

Our results are similar to the findings of Ismail and Szpunar (11), suggesting a lack of significant association between acculturation and the number of decayed teeth. Acculturation was associated positively with younger age, higher education \& income and more years of duration of stay and these findings are similar to study by Gustavo et al ,Cruz et al $(10,14)$.

Language barrier made it difficult to communicate the affected oral the health between dentist and patient in turn significantly associated with dental caries and periodontal status. These findings are similar to the study conducted by Micheale A. Graham et al (6). Those who lived in Bangalore for 4 years or more and who can communicate in English appear to have better oral health and most likely to get dental checkup.

Acculturation and language utility have been shown to affect not only whether a group has access to dental care but also whether its members seek treatment (Francisco et al 2005) ${ }^{17}$.The present study suggests that their overall oral health doesn't worsen as they become more acculturated. On the contrary, the more acculturation they become, the more oral health benefits were seen.

This study is limited in its generalization due to its sampling methodology nevertheless; this is the first study of its kind reported in India on a group of adult immigrants. Thus, it provides valuable information on the effects of acculturation on the oral health outcomes of a less established group of individuals. Through information secessions and by distribution of study material at immigrants could learn and improve their management of oral health and illness and thus facilitate their communication with dentists as well as their adoption to the culture of their new country.

Understanding and characterizing the process of cultural change is essential to the conduct of relevant health intervention. Basic services and health promotion activities should be made available to the immigrant population. Acculturation positively influences the oral health of these individuals by mediating their access to preventive and restorative oral heath. Language is directly an important factor that should be considered during oral health education and treatment procedures. Preventive programmes should be organized at local community level in collaboration with key persons of the immigrant population 


\section{Acknowledgements}

The authors are very greatful to the participants for their contribution, as well as to the Tibetan community centre.

\section{References}

1. Lara M, Gamboa C, Kahramanjan MI, Morales LS, Bautista DE. Acculturation and Latino health in the United States: a review of the literature and its Sociopolitical context .Annu Rev public Health 2005:26:367-97.

2. Hazuda HP et al. Effects of Acculturation and socioeconomic status on obesity and diabetes in Mexican-americans. The San Antonio Heart Study. Am J Epidemiol 1988:128:1289-1301.

3. Balcazar H,Castro FG,Krull JL. Cancer risk reduction in Mexican American women:the role of acculturation, education and health risk factors. Health Educ Q 1995:22:61-84.

4. Franzini L, Ferandez Esquor ME. Socio-Economic, cultural and personal influences on health outcomes in low income MexicanAmerican origin individual in Texas. Soc Sci Med 2004; 59:162946.

5. Fernando S. Mendoza, Health Disparities and Children in Immigrant Families: A Research Agenda PEDIATRICS Vol. $124 \mathrm{Su}-$ pplement November 2009, pp. S187-S195

6. Michelle A Graham, Scott L. Tomar and Henrietta L Logan. Percieved social status, language and identified dental home among Hispanics in Florida. JADA 2005 Nov:Vol 136:1572-1582.

7. Robertson J A McL et al. A dental survey of Tibetian children in Dharmashala. Community Dent Oral Epidemiol 1989:7:44-46.

8. Jiru Otsuru, Ueno Masayunki, Kayoko Shinada, Vladimir W.Spolsky, Cal A.Maida etal. A comparative study of oral health status in a migrant/Japanesese sample.J Med Dent Sci 2006; 53:2733.

9. Cruz GD, Chen Y, Salazar CR, Le Geros RS The association of immigration and acculturation attributes with oral health among immigrants in New York City.Am J Public Health Oct;99 Suppl 2:S474-80. Epub 2009 May 14.

10. Gustavo D et al. Dental caries experience, tooth loss and factors associated with unmet needs of Haitian immigrants in New York City. J Public Health Dent 2001:61(4):203-209.

11. Ismail AI, Szpunar SM. Oral health status of Mexican-Americans with low and High Acculturation status. J Public Health Dent 1990:50:24-31.

12. Marino R, Stuart G W, Wright FA, Minas IH, Klimidis S. Acculturation and dental heath among Vietnamese living in Melbourne, Austria, CDOE 2001;29(2):107-119.

13. Stewart,Ortega AN, Dausey D, Rosenheck R. Oral health and use of dental services among Hispanics. Journal of Public Health Dentistry 2002;62(1):84-91.

14. G.D.Cruz et al. Effect of Acculturation on objective measures of oral health in Haitian immigrants in Newyork city. J Dent Res 2004:83(2):180-184.

15. Christopher Okunseri et al. Hmong adults self-rated oralhealth:A pilot study. J Immigrant Minority Health 2008:10:81-88.

16. Okunseri C, Yang M, Gonzales JS,Born DO : Self-reported oral health perception of Somali adults in Minnesota:a pilot study.Int J Dent Hygiene 2008:6:114-118.

17. Francisco Ramos et al. Latino oral health. A research agenda towards eliminating Oral health disparities. JADA 2005:136(9):12311240 . 